\title{
Construção de redes e agroecologia: o papel dos atores sociais no desenvolvimento rural
}

\author{
Construction of networks and agroecology: the role of social actors in rural \\ development

\section{Construction de réseaux et agroécologie: le rôle des acteurs sociaux dans le développement rural}

\section{Construcción de redes y agroecología: el papel de los actores sociales en el desarrollo rural}

Filipe Augusto Xavier Lima ${ }^{1}$ DOI: http://dx.doi.org/10.20435/inter.v0i0.1696

\begin{abstract}
Resumo: Este trabalho identifica e analisa os padrões de interação entre atores sociais e o caráter específico que eles imprimem em dinâmicas de desenvolvimento rural pautadas na Agroecologia. Para isso, elegeuse uma análise comparativa entre dois casos de transição agroecológica no estado de Pernambuco, que demonstra que é possível identificar fatores que qualitativamente produzem diferenças entre casos concretos, e que tais fatores podem levar a dinâmicas mais ou menos sustentáveis no tempo.
\end{abstract}

Palavras-chave: agricultores; assentamento rural; transição agroecológica.

Abstract: This work identifies and analyzes the interaction patterns among social actors and the specific character they assign to rural development dynamics based on Agroecology. In this regard, a comparative analysis between two cases of agroecological transition of Pernambuco state was performed, revealing that it is possible to identify factors that qualitatively leads to differences between concrete cases, as well as that such factors could induce more or less sustainable dynamics over the time.

Keywords: farmers; rural settlement; agroecological transition.

Résumé: Ce document identifie et analyse les modes d'interaction entre les acteurs sociaux et le caractère spécifique qu'ils impriment dans la dynamique de développement rural basée sur l'Agroécologie. Pour cela, il a été élu une analyse comparative des deux cas de transition agroécologique dans l'état de Pernambuco, ce qui démontre qu'il est possible d'identifier les facteurs qui produisent des différences qualitatives entre les cas individuels, et que ces facteurs peuvent conduire à une dynamique plus ou moins durables dans le temps. Mots-clés: agriculteurs; établissement rural; transition agro-écologique.

Resumen: Este trabajo identifica y analiza los patrones de interacción entre actores sociales y el carácter específico que ellos imprimen en dinámicas de desarrollo rural pautadas en la Agroecología. Para ello, se eligió un análisis comparativo entre dos casos de transición agroecológica en el estado de Pernambuco, que demuestra que es posible identificar factores que cualitativamente producen diferencias entre casos concretos, y que tales factores pueden llevar a dinámicas más o menos sostenibles en el tiempo.

Palabras clave: agricultores; asentamiento rural; transición agroecológica.

\section{INTRODUÇÃO}

Contemporaneamente, nas concepções de desenvolvimento, o meio rural tem um importante papel, e a sua função de fornecimento de matérias-primas e mão de obra para o crescimento econômico é cada vez menos essencial, frente aos próprios atributos territoriais que definem a ruralidade e que oferecem perspectivas otimistas ao desenvolvimento. São eles: certa relação com a natureza, onde a biodiversidade e a paisagem natural aparecem como trunfos, e não como obstáculos ao desenvolvimento; certa relação com as cidades, de onde vem boa

\footnotetext{
${ }^{1}$ Universidade Federal do Ceará (UFC), Fortaleza, Ceará, Brasil.
} 
parte das rendas das populações rurais; e certa relação dos habitantes entre si, definida pela economia da proximidade e por um conjunto de laços sociais que valorizam relações diretas de interconhecimento (ABRAMOVAY, 2009).

Entender os fatores que levam determinadas regiões a se tornarem mais dinâmicas do que outras não é simples, mas isso pode estar relacionado a uma densa rede de relações entre serviços e organizações públicas, iniciativas empresariais urbanas e rurais, agrícolas e não agrícolas. $\mathrm{Na}$ opinião de Abramovay (2009), o mais importante não são as vantagens competitivas oferecidas por atributos naturais, de localização ou setoriais, e sim o fenômeno da proximidade social, que possibilita uma forma de coordenação entre os atores, capaz de fortalecer o conjunto do ambiente em que atuam e, com efeito, de convertê-lo em pilar para empreendimentos inovadores.

Trata-se de um tipo de situação que sugere relações diretas entre os atores e que, em torno do desenvolvimento rural, fez com que emergisse uma corrente de pensamento que enfatiza a dimensão territorial do desenvolvimento, estudando a montagem de redes, das convenções e das instituições que permitem ações cooperativas - capazes de enriquecer o tecido social de certa localidade (ABRAMOVAY, 2009). Nessa perspectiva, a rede social pode ser definida como um conjunto de nós ou atores (pessoas ou organizações) ligados por relações sociais ou laços de um tipo especificado (CASTILLA et al., 2000). As redes também podem ser entendidas como um conjunto regular de contratos ou conexões sociais entre indivíduos ou grupos (GRANOVETTER; SWEDBERG, 2011).

Sobre essa constituição de redes, neste artigo, realiza-se um estudo comparativo a partir de dois municípios do estado de Pernambuco: Santa Cruz da Baixa Verde, na mesorregião do Sertão, e São Lourenço da Mata, localizado na Região Metropolitana de Recife (RMR). Voltados anteriormente para a agricultura pautada no monocultivo da cana-de-açúcar, ambos os municípios concentram, atualmente, experiências de desenvolvimento rural em processo de transição agroecológica, as quais se desenvolveram, no primeiro caso, ainda na década de 1990 e, no segundo caso, em meados dos anos 2000. A pesquisa tem como base dois estudos de caso específicos, em que o "universo empírico" (atores sociais) são os agricultores familiares de Santa Cruz da Baixa Verde, ligados à Associação de Desenvolvimento Rural Sustentável da Serra da Baixa Verde (ADESSU), e os agricultores familiares do assentamento de reforma agrária Chico Mendes III, em São Lourenço da Mata.

Sujeitos aos mesmos efeitos de um modelo de agricultura de caráter predatório para as populações rurais menos favorecidas, os processos de transição agroecológica desses dois municípios foram motivados, contudo, por combinações particulares de estratégias de desenvolvimento rural e por contextos locais significativamente diferentes. A partir dessa realidade, cabe observar: 1) De que maneira atores e redes sociais podem influenciar o desenvolvimento rural? 2) Como isso vem acontecendo? 3) Quem são os atores envolvidos? 4) Como ocorrem as interações entre eles? Enfim, 5) Quais as diferenças entre as experiências em termos qualitativos?

Assim, este trabalho tem como principal objetivo identificar e analisar os padrões de interação entre os atores e o caráter específico que eles imprimem na dinâmica de desenvolvimento rural vivenciada pelos agricultores da ADESSU e do assentamento Chico Mendes III. Um estudo das experiências de desenvolvimento rural pautadas na Agroecologia e na construção de redes sociais, e estabelecidas em configurações particulares de grupos de agricultores familiares, torna-se importante por pelo menos duas razões. Em primeiro lugar, entender as relações existentes entre 
os agricultores familiares que se orientam pelos princípios da Agroecologia e outros atores locais pode ajudar a revelar particularidades do desenvolvimento rural e auxiliar os grupos envolvidos a avaliarem suas estratégias. Em segundo lugar, uma análise que confronte as particularidades de estratégias de desenvolvimento rural em contextos locais diferentes, assim como as suas consequências, pode servir como uma contribuição para o aprimoramento das políticas de assistência técnica e extensão rural (ATER) voltadas aos agricultores familiares.

\section{METODOLOGIA}

Na análise comparativa, a observação direta tornou-se um procedimento frequente para a coleta de dados, ocorrendo nas unidades de produção agropecuária (UPAs) dos agricultores de base agroecológica ligados à ADESSU e ao assentamento Chico Mendes III, nas feiras agroecológicas onde são comercializados os produtos e nos locais onde os agricultores costumam se reunir. Nessa etapa, procurou-se escrever todas as informações que não fariam parte do material formal de entrevistas, além de apreciar o trabalho desenvolvido pelas instituições que apoiam os agricultores na transição agroecológica. Por esse meio, acredita-se que foi possível começar a identificar e analisar os padrões de interação entre os atores que participam das experiências.

Foi delineado o levantamento de dados, primeiramente a partir de entrevistas direcionadas a fontes-chave de informação, em que foram considerados neste estudo os agricultores que vivenciaram os processos de transição agroecológica desde o início de sua implementação, alguns dos ex-presidentes e o atual presidente da ADESSU, agricultores-experimentadoresmultiplicadores do assentamento Chico Mendes III, extensionistas locais e professores e estagiários da Universidade Federal Rural de Pernambuco (UFRPE) ligados ao Núcleo de Agroecologia e Campesinato (NAC).

Na sequência, as entrevistas com base em um roteiro estruturado se estenderam aos agricultores associados à ADESSU e aos representantes de cada família assentada no Chico Mendes III. Com a realização do trabalho de campo, na experiência da ADESSU foram entrevistados três fontes-chave (um extensionista do Instituto Agronômico de Pernambuco [IPA], um ex-presidente da associação e um jovem "difusor em Agroecologia"). Do lado do assentamento, foram ouvidos quatro fontes-chave (um técnico-administrativo e três estagiários da UFRPE ligados aos projetos do NAC). As entrevistas seguiram para seis agricultores associados à ADESSU e para sete representantes das famílias assentadas, mas convergindo sobre os mesmos temas.

Todas as entrevistas foram gravadas e, depois de transcritas, formaram um documento, a partir do qual foram retiradas as principais falas dos discursos dos agricultores e das fontes-chave. Para a transformação dos discursos dos entrevistados em textos formais presentes neste artigo, e com o objetivo de manter o anonimato de cada informante, foram utilizadas siglas seguidas de um número. Então, os agricultores da ADESSU foram denominados de AAD, as fontes-chave ligadas à ADESSU foram denominadas de FCAD, os agricultores assentados do Chico Mendes III foram denominados de ACM e as fontes-chave ligadas ao assentamento, de FCCM. No que diz respeito à transformação do discurso dos entrevistados em textos formais, procurou-se deixá-lo o mais fiel possível às ideias e argumentações das pessoas ouvidas. A intenção foi registrar a voz dos principais protagonistas da presente pesquisa sem deformações. Procurou-se comprovar seus discursos, na medida do possível, por meio de alguns registros escritos e constatações derivadas da observação direta. 


\section{RESULTADOS E DISCUSSÃO}

Entendida como uma ciência ou disciplina científica, a Agroecologia apresenta uma série de princípios, conceitos e metodologias baseados na aplicação da Ecologia, para o estudo, desenho e manejo de agroecossistemas sustentáveis, com o propósito de permitir a implantação e o desenvolvimento de estilos de agricultura sustentáveis, nas suas diversas manifestações ou denominações (ALTIERI, 2012).

A respeito da transição agroecológica, Caporal e Costabeber (2007) afirmam que ela pode ser definida como um processo gradual de mudança, que ocorre ao longo do tempo, nas formas de manejo e gestão dos agroecossistemas, tendo como objetivo a passagem de um sistema de produção convencional a outro sistema de produção que incorpore princípios, métodos e tecnologias de base ecológica.

Um traço marcante na trajetória do processo de transição agroecológica dos agricultores da ADESSU é a participação contínua de outros atores locais. As primeiras parcerias a se formar em Santa Cruz da Baixa Verde, ainda na década de 1990, resultaram de iniciativas de agricultores convencionais que vinham enfrentando os efeitos negativos de um modelo de agricultura capitalista e excludente, pautado, sobretudo, no monocultivo da cana-de-açúcar. A exploração da mão de obra e a falta de perspectiva socioeconômica que garantisse a reprodução da agricultura familiar foram alguns dos fatores que levaram esses agricultores a se envolver na proposta de transição agroecológica, como relata um dos fontes-chave, contando suas próprias dificuldades enfrentadas na época:

Muitos agricultores iam para os centros urbanos trabalhar de ajudante geral. Porque a gente sem estudo não tem profissão. Muitos se marginalizaram e outros voltaram, que nem eu, também. Eu passei dois anos no Mato Grosso e seis meses em Minas, e saí justamente por conta disso, aqui não dava condições. Trabalhei na agricultura e em restaurante, retornei com o propósito de não ter que voltar mais para outra região, e eu cheguei no momento que o grupo que ficou estava discutindo a fundação da ADESSU e eu me reintegrei ao grupo e estou aqui até hoje. Esses agricultores que fundaram a ADESSU eram bem diversificados: tinham os mais velhos aposentados, a maioria de jovens, um percentual de mulheres. Tinham uns que trabalhavam nos engenhos no verão, para poder ganhar dinheiro e no inverno plantavam cana também, plantava milho, feijão. Eu sei que todos estavam envolvidos na atividade agrícola, só que a atividade não estava respondendo financeiramente, por isso que fomos atrás de outra forma de trabalhar, que fosse sustentável, que gerasse renda e preservasse o meio ambiente para as gerações futuras. (FCAD1).

Naquele momento, ficou evidente a importância que teriam os atores locais para o processo de transição agroecológica dos agricultores do município, a exemplo do Sindicato dos Trabalhadores Rurais de Triunfo, que construiu a parceria com outros atores sociais e buscou novos projetos que pudessem fortalecer a experiência dos agricultores envolvidos, o que culminou na criação da ADESSU.

Como descrito por Schmitt (2011), a costura de redes, mobilizando relações, recursos e significados, é capaz de promover a interconexão entre distintas realidades e formas de conhecimento, ultrapassando domínios institucionais específicos e conectando uma diversidade de interesses. Para a autora, "é na confluência entre essas múltiplas realidades, e através de processos de luta, negociação e acomodação, em diferentes campos de batalha, que se constrói o desenvolvimento" (SCHMITT, 2011, p. 92). Essa fase inicial de construção de redes é também detalhada na fala do fonte-chave FCAD1: 
Dentro do grupo ligado ao sindicato, a gente sentiu a necessidade de fazer algo relacionado à agricultura e relacionado à renda também, para fixar o jovem no campo. Foi aí que a gente criou uma equipe de agricultura, apoiada pelo Sindicato dos Trabalhadores Rurais de Triunfo, e começou a se discutir os impactos causados pela agricultura convencional e vieram as propostas de mudança, só que a gente não tinha muito apoio. O sindicato conseguiu um projeto com uma cooperação alemã e veio uma técnica da Alemanha, que passou cinco anos com a gente e deu uma estrutura a essa equipe de agricultura. (FCAD1).

A adesão de novos agricultores à proposta agroecológica da ADESSU foi evoluindo ao longo dos anos, fruto de um esforço conjunto entre a associação e as instituições parceiras atuantes no município de Santa Cruz da Baixa Verde. Costabeber, Garrido e Moyano (2000) utilizam-se da argumentação de que os agricultores que ingressam em propostas de agricultura de base ecológica sentem a necessidade de articulação de seus interesses particulares mediante estratégias de ações coletivas. Tais ações partem da própria perseverança dos agricultores em aperfeiçoar seu trabalho e procurar os instrumentos e apoios para dar continuidade aos seus projetos de agricultura sustentável. Então, o processo de ação social coletiva se transforma no propulsor da transição agroecológica, podendo resultar no alcance de objetivos econômicos, sociais e ambientais que assegurem a continuidade da "ecologização" da agricultura (COSTABEBER, GARRIDO; MOYANO, 2000).

O entrevistado FCAD3 expõe que, além da mudança na diversidade produtiva nas UPAs dos associados e do melhor aproveitamento dos recursos naturais, merece destaque a organização social presente na experiência da ADESSU, bem como a questão financeira, que, segundo ele, sofreu uma transformação positiva, já que os agricultores passaram a acessar novos canais de comercialização, como os programas governamentais. Diz ele:

Mudou principalmente a questão do conhecimento, no que diz respeito à organização social e principalmente à questão da comercialização, por eles estarem organizados, por eles terem essa visibilidade, por trabalharem com os princípios da Agroecologia, fica até melhor para estarem comercializando e acessando alguns canais, como o Programa de Aquisição de Alimentos (PAA) e o Programa Nacional de Alimentação Escolar (PNAE), que são alguns canais que eles acessaram. (FCAD3).

As características dos atores presentes na experiência de Santa Cruz da Baixa Verde e o tipo de relação que se estabelece entre eles se revelaram fundamentais tanto para entender os padrões de interação com os agricultores da ADESSU como para avaliar a qualidade dos efeitos de transbordamento dos resultados da transição agroecológica sobre a agricultura familiar local.

No início da experiência da ADESSU, os agricultores associados receberam um importante apoio dos sindicatos dos trabalhadores rurais locais e da organização não governamental (ONG) Centro de Desenvolvimento Agroecológico Sabiá, direcionado principalmente para o processo formativo do grupo. A ideia-chave era que cada agricultor implantasse uma agrofloresta em suas propriedades, para fins produtivos, e, assim, garantisse a sua reprodução socioeconômica. Além disso, foram sendo estabelecidos e discutidos os critérios para o acesso e permanência dos sócios na ADESSU, sendo que, em um primeiro momento, as orientações estavam voltadas para a extinção das práticas nocivas ao meio ambiente em suas áreas, como as queimadas e a adubação química (FCAD1).

O Centro Sabiá parece ter tido papel fundamental para o processo de transição agroecológica, devido à sua participação junto aos agricultores, nas fases de planejamento e execução das ações. Os outros parceiros citados, mas considerados eventuais, foram o Centro de Educação Comunitária 
Rural (CECOR), sindicatos de trabalhadores rurais, prefeituras, outras associações e os Conselhos Municipais de Desenvolvimento Rural Sustentável (CMDRSs). Na opinião do entrevistado FCAD1, a articulação entre a ADESSU e esses parceiros sempre existiu: "A gente se articulou entre si o coletivo, claro que uns com maior e outros com menor intensidade, até mesmo com aqueles que apresentam a filosofia de trabalho diferente, como é o caso do sindicato".

O informante FCAD 2 alega que, além do Centro Sabiá e os outros atores citados, merecem destaque, também, as organizações internacionais financiadoras de projetos envolvidas na experiência, cuja principal é a Kindernothlife (KNH). O entrevistado afirma que essa parceria, iniciada em 2003, teve um papel essencial na transição agroecológica, sobretudo após o projeto do protagonismo infantojuvenil.

Esse apoio relatado, da parte dos agricultores ouvidos, fica mais a cargo da ADESSU, que é quem busca essa articulação com as outras organizações e instituições, além de ser a responsável pela assessoria técnica prestada aos agricultores associados, enviando jovens "difusores" ou monitores mensalmente para o acompanhamento das suas produções.

O CECOR, que é outra ONG presente na experiência dos agricultores da ADESSU, segundo relatos, tem papel mais relevante na organização da Feira Agroecológica de Serra Talhada (FAST), com reunião mensal para tratar desse espaço para a comercialização dos produtos agroecológicos dos associados. Alguns agricultores, inclusive, citam já ter recebido visita do CECOR em suas propriedades, porém reconhecem que a sua atuação é mesmo referente à FAST. O Instituto Agronômico de Pernambuco (IPA), instituição governamental de âmbito estadual que atua na localidade por meio de seu escritório municipal, também teve sua atuação reconhecida, mesmo que de forma pontual, visto que sua atuação não abrange todos os sócios da ADESSU.

Os resultados das parcerias que foram sendo intensificadas na experiência da ADESSU, ao longo dos anos, fizeram com que a associação fosse reconhecida, hoje em dia, em nível estadual, regional, nacional e até internacional, na visão do entrevistado FCAD1, que acrescenta que a ADESSU não chegaria tão longe sem esse trabalho conjunto para divulgar e expandir todo o processo de transição agroecológica. Para o fonte-chave FCAD2, sem essas parcerias, não seria possível atuar no número de comunidades que hoje são assistidas pela ADESSU, com o acompanhamento direto ou indireto de cerca de 1.500 famílias, por conta dos projetos em curso. O mesmo fonte-chave FCAD2 situa que, depois das parcerias, a ADESSU passou a ter mais autonomia nas suas ações, citando como exemplo o trabalho de assistência técnica que ultimamente é oferecido pela própria associação, algo que antes não existia.

Do mesmo modo, o conhecimento adquirido pode ser apontado com um aspecto positivo emergente da existência das parcerias com outras instituições, para os associados. A alegação vem a partir do reconhecimento do trabalho dos jovens "difusores em Agroecologia" da ADESSU, que, ao entrarem em contato com outros atores, atualizam-se e, na sequência, socializam as novas informações com os demais agricultores, num fluxo contínuo de introdução e multiplicação de novos conhecimentos.

Atualmente, os entrevistados consideram que as parcerias com outros atores sociais permanecem no caso da ADESSU, mesmo que a atuação ocorra de forma indireta, ou, ainda, em maior ou menor grau de envolvimento, a depender de cada instituição específica. Os agricultores entendem o possível afastamento de algumas instituições parceiras como algo natural e enxergam duas razões principais para esse fato. A primeira é que as demandas das organizações ou instituições tiveram um crescimento significativo nos últimos anos, fazendo com que as suas 
prioridades passassem a ser aquelas experiências de agricultores familiares em estágio ainda incipiente. A segunda, e mais importante, é que os agricultores da ADESSU não se enxergam em uma situação de dependência dessas instituições ou organizações, fato que se deve, segundo a avaliação de muitos associados da ADESSU, ao nível de organização atingido pela associação.

Em poucas palavras, importa destacar que a articulação entre a ADESSU e outros atores locais é bastante comum e vai desde o compartilhamento informal do conhecimento agroecológico até a elaboração de atividades formais de várias ordens, como o desenvolvimento conjunto de ações que busquem a melhoria socioeconômica e produtiva das famílias envolvidas na transição. Nesse estreitamento de laços, é imprescindível conceber que as redes, além de se constituírem em formas de inserção econômica e de reprodução social, potencializam os vínculos políticos, as associações nas comunidades rurais, as cooperativas e as ações coletivas, expressando a pluralidade de empreender esforços para o desenvolvimento rural (RADOMSKY, 2006). Por fim, no campo da interação entre os distintos atores presentes em Santa Cruz da Baixa Verde, está um ambiente propício para a disseminação de ideias voltadas para a construção de estilos de desenvolvimento rural e de agriculturas sustentáveis. Elas encorajam não só a adesão de novos agricultores à experiência, como também o desenvolvimento de novos projetos.

No caso de São Lourenço da Mata, estavam ausentes praticamente todos os elementos que colaboraram para o desenvolvimento relativamente endógeno e gradual do processo de transição agroecológica observado em Santa Cruz da Baixa Verde. A rigor, os atores que desempenharam papel relevante no assentamento Chico Mendes III não têm os fortes vínculos observados no município sertanejo. Segundo um dos fontes-chave entrevistados, a forma de viabilizar a experiência surge a partir da demanda do Movimento dos Trabalhadores Rurais Sem Terra (MST), com a criação de novos assentamentos em Pernambuco e a orientação de se trabalhar numa perspectiva de agricultura de base ecológica com as famílias assentadas, dentro dos princípios da Agroecologia (FCCM1). Para isso, ainda segundo esse mesmo fonte-chave, a UFRPE foi procurada para dar esse suporte através de projetos e programas de pesquisa e extensão na localidade. O FCCM2 caracteriza, em síntese, como se deu a participação da universidade na iniciativa e o quanto isso foi significativo para os assentados:

A UFRPE atuou como orientadora do processo. É quem dava o suporte que os agricultores precisavam para a realização das ações. Eu entendo que, com isso, os assentados passaram a ter uma motivação maior para trabalharem no próprio assentamento, passaram a estarem mais presentes no dia a dia do assentamento. E isso melhorou até a autoestima deles. (FCCM2).

O informante FCCM3 é mais um que destaca a participação da UFRPE na experiência, porém ele recorda que, ainda durante a fase de acampamento, os trabalhadores acampados já discutiam a necessidade de se organizar e a possibilidade de implementar um cultivo orgânico na área. "Isso partiu deles, muitos ainda adubavam quimicamente e outros usavam inseticidas químicos também. Depois, com a pressão do MST, com a capacitação da universidade, viram que era promissor, viram a necessidade de aderir a essa transição (FCCM3)".

Dentro dessa mesma linha de pensamento, uma assentada entrevistada confirma as informações anteriores, recordando a orientação do MST em se trabalhar com outro modelo de agricultura e como ocorreu a entrada da universidade no assentamento.

[...] Quando a gente ganhasse a terra, esse assentamento ia ser modelo, e a gente ia passar a trabalhar com orgânico. A gente não poderia usar veneno, a gente concordou e continuou 
não usando veneno. Em janeiro de 2009, o professor e a universidade entraram aqui dentro. O professor apresentou um roçado de estudo pra gente trabalhar com orgânico, e a gente concordou. Ele disse: olha, a gente vem pra cá, se vocês concordarem em trabalhar com orgânico, sem usar agrotóxico e veneno. A gente tudinho concordou. Ele disse: a gente traz experiência pra vocês e vocês dão experiência para nós. (ACM3).

Embora essa troca de experiências tenha ocorrido durante todas as etapas do projeto de transição agroecológica no assentamento, importa sublinhar que, no caso do Chico Mendes III, a UFRPE exerceu um forte e quase solitário protagonismo inicial, e o quadro de condições e atores preexistentes praticamente não influenciou o desenho da estratégia de desenvolvimento adotada. Fontes-chave identificam, no perfil diversificado dos assentados e na precária situação das famílias, as principais razões para que os agricultores desempenhassem apenas um papel secundário nessa experiência.

Com certeza, o diferente perfil dos trabalhadores residentes no assentamento comprometeu o nível de participação e envolvimento no projeto proposto, participação essa assinalada como:

Condição essencial, pois é instrumento de mobilização social que fortalece os laços comunitários e o sentido comum, com a finalidade de desencadear processos de ação social coletiva nos quais as pessoas reconhecem o valor dos recursos e demais elementos constituintes de uma condição local (muitas vezes assinalada como marginal), com fins de estabelecer planos de longo prazo, numa perspectiva de desenvolvimento endógeno. Para a Agroecologia, a incorporação da participação como pressuposto epistemológico permite ganhos em conhecimento e em criatividade, assim como permite estabelecer processos transformadores de longo prazo. (GOMES; BORBA, 2004, p. 10).

De certo, a UFRPE vem exercendo um importante papel no caso do assentamento; com efeito, já é possível reconhecer que o conhecimento agroecológico, antes ausente entre a maioria dos agricultores, vem sendo paulatinamente construído e socializado entre eles. Para o informante FCCM1, a construção desse conhecimento agroecológico se deu justamente após a chegada da universidade, e isso se traduziu em algumas mudanças, que vão desde a diversificação nos sistemas produtivos dos assentados até um maior engajamento político a favor de suas reivindicações.

Para o entrevistado FCCM4, o acompanhamento da UFRPE é importante, porém não é suficiente para sanar os problemas das famílias que ali residem. Em sua opinião, inclusive, os agricultores estão em uma situação quase que de abandono, negligenciados pelo Estado:

A universidade é muito importante, mas não resolve tudo. É uma instituição de educação, ela tem as suas contribuições e responsabilidade, mas ali falta o papel do Estado, do movimento, do Estado para dar continuidade à reforma agrária, à ATER, falta esses agentes. Isso é muito importante, falta esse trabalho. Às vezes a gente quer melhorar a produção, mas o produtor está passando por necessidades básicas. É preocupante a ausência do Estado no assentamento. (FCCM4).

Em oposição ao tom bastante positivo com que os entrevistados de Santa Cruz da Baixa Verde se referem ao associativismo agrícola local, em São Lourenço da Mata, os relatos são muito críticos em relação à atuação das ações coletivas no assentamento. O informante FCCM2 considera que, "enquanto integrantes de um movimento social, a organização deles é perfeita, mas, no momento de um trabalho em conjunto para a produção, parecia que sempre havia algum tipo de desencontro entre eles mesmos". A mobilização coletiva é uma limitação categórica na experiência e precisa ser melhorada, para que as formas de organização dos agricultores e de 
outros atores socioeconômicos possam participar da reprodução ou da atualização de relações estruturais econômicas e sociais de reciprocidade, como ensina Sabourin (2006). Para esse autor:

São essas relações e estruturas que têm conseguido mesmo se ignoradas ou mascaradas e apesar da dominação do sistema de intercâmbio capitalista, assegurar a sobrevivência material da maioria das populações rurais e, sobretudo, a manter nas nossas sociedades, um mínimo de valores humanos. (SABOURIN, 2006, p. 233).

Em vez de receber assessoria de agentes de assistência técnica e extensão rural (ATER) de instituições governamentais ou de ONGs voltadas ao desenvolvimento rural, como acontece com os associados da ADESSU, hoje em dia, os assentados do Chico Mendes III contam apenas como a assistência dos bolsistas ligados aos projetos da UFRPE, ou, ainda, com o auxílio informal de estudantes de cursos como Ciências Biológicas, Agronomia, Medicina Veterinária ou Zootecnia, que são levados para realizarem algum tipo de atividade pedagógica prática no assentamento.

Um aspecto negativo apontado pelos agricultores entrevistados é sobre a comercialização dos produtos, mais precisamente pela falta do envolvimento dos assentados na feira agroecológica que foi criada no Recife para a venda de suas produções e na parte do transporte das suas mercadorias. A assentada ACM5 afirma que o fato de poucas pessoas estarem inseridas na feira tem ocasionado prejuízos para aqueles que vão com regularidade, pois isso encarece os custos com o transporte, dividido entre eles.

Esse tipo de situação é considerado por eles mesmos como uma clara representação da falta de associativismo e cooperativismo em prol de um benefício conjunto e em comum para todos. O alcance das redes sociais, que não é percebido no assentamento, poderia influenciar os resultados econômicos, "alterando o fluxo e a qualidade da informação; favorecendo a mobilização de recursos; institucionalizando mecanismos de retribuição ou de punição; possibilitando a estruturação (ou desestruturação) de vínculos de confiança" (SCHIMITT, 2011, p. 98).

O processo de transição agroecológica do assentamento Chico Mendes III mediante o incentivo de uma instituição de ensino superior originou uma configuração completamente diferente da configuração da ADESSU. A trajetória da experiência teve início com projetos de pesquisa e de extensão universitária, por meio do Núcleo de Agroecologia e Campesinato (NAC), vinculado ao Departamento de Educação da UFRPE. Desde então, é feito um trabalho de acompanhamento das famílias que vivem no assentamento, por intermédio dos professores e estudantes estagiários vinculados aos diferentes projetos que permanecem em andamento.

O FCCM 1 é da opinião de que existiu certa articulação entre a UFRPE, que atuou no serviço de extensão, e o MST, responsável pela mobilização e organização política dos assentados. Esse informante também defende que, indiretamente, houve a participação de outras instituições e organizações, inclusive do IPA e do Centro Sabiá, que são parceiros mais engajados na experiência da ADESSU. Porém a participação dos outros atores não é considerada representativa, pois limitou-se somente ao apoio em alguns cursos, intercâmbios, vacinação de animais, treinamentos ou capacitações técnicas.

Segundo o informante FCCM3, falta, em parte dos assentados, um maior enraizamento socioprodutivo, o que vem impedindo que alguns deles adquiram o sentimento de pertencimento à transição agroecológica. É provável que isso venha retardando a construção da identidade do grupo, o que, para Castells (2008), quando ligada a atores sociais, dá-se com base em um atributo cultural, ou ainda um conjunto de atributos culturais inter-relacionados, os quais prevalecem sobre outras fontes de significado. No entanto, como adverte o autor, "essa pluralidade é fonte 
de tensão e contradição tanto na autorrepresentação quanto na ação social" (CASTELLS, 2008, p. 22). Por conseguinte as ações coletivas ficam comprometidas, gerando uma situação de dependência por parte dos assentados, na medida em que ganha força a ideia de que somente a universidade deve buscar as soluções necessárias para o assentamento (FCCM3). A assentada ACM2 concorda com essa conjuntura, explicando que a principal consequência disso é a falta de autonomia do grupo. Autonomia essa que conduz diretamente ao problema político e social e que, ao mesmo tempo, não pode ser desejada sem almejá-la para todos, fazendo com que sua realização só possa conceber-se plenamente como empreitada coletiva (CASTORIADIS, 1982).

Ainda, foram levantadas informações para situar como está, atualmente, a atuação das organizações ou instituições envolvidas no caso do Chico Mendes III. Com as respostas obtidas, averiguou-se que a universidade vem conseguindo renovar aqueles projetos já em andamento ou, até mesmo, aprovar novas iniciativas para o assentamento, sendo que já se tem um importante projeto financiado pelo Conselho Nacional de Desenvolvimento Científico e Tecnológico (CNPq) para ser executado nos próximos anos.

Um indicador importante das diferenças entre os dois casos analisados é o nível de participação nas estratégias de desenvolvimento rural sustentável ou no processo de transição agroecológica, participação entendida aqui não como um indicador fixo, mas como uma posição na qual as pessoas podem ganhar mais ou menos graus de envolvimento na dinâmica de desenvolvimento (GEILFUS, 2009).

Ainda no dizer de Geilfus (2009), a participação efetiva começa ao menos a partir do nível funcional, no qual as pessoas têm capacidade de modificar e ajustar as atividades, mas a participação buscada é a interativa, para desencadear na autonomia do coletivo, que chegaria a gerar práticas de autodesenvolvimento. Em Santa Cruz da Baixa Verde, pode-se dizer que o envolvimento dos agricultores da ADESSU extrapola, há algum tempo, o nível de participação considerado como ideal, e isso tem resultado em projetos coletivos dos agricultores familiares junto aos parceiros presentes na experiência.

Já em São Lourenço da Mata, como a maior parte dos assentados se reconhece como dependente das ações da UFRPE, a participação não ultrapassa o seu nível funcional, pois, quando ela ocorre, fica, na melhor das hipóteses, no nível da participação por incentivos. Isso não significa dizer que os agricultores do assentamento Chico Mendes III estão em avançado estágio de passividade ou não têm condições de alcançar o próximo nível; pelo contrário, o projeto caminha nessa direção, entretanto essa passagem tem obstáculos a serem superados e requer um esforço de todo o coletivo. Certamente, após essa conquista, a participação dos atores deixará de acontecer apenas em atividades marginais e poderá ser utilizada para o aperfeiçoamento da estratégia de desenvolvimento rural sustentável do assentamento.

Além do mais, há de se convir que a forma de participação dependa dos tipos de redes sociais estruturadas em cada experiência, o que pode favorecer ou dificultar a inserção dos agricultores nos processos de transição agroecológica. Não é intenção aqui gerar um ranking a partir dos níveis de participação identificados nos dois casos e dizer qual é a mais adequada. Até porque, como se viu, a ADESSU e o assentamento Chico Mendes III estão em considerável disparidade em suas relações institucionais, o que faz toda a diferença em experiências como essas.

Vale lembrar que, como previne Schultz (2011), as organizações (cooperativas e associações), ausentes no assentamento, são as principais relações institucionais para os agricultores, por meio da promoção e regulação das suas atividades profissionais exercidas nas propriedades. 
São elas que atuam na gestão das relações com o mercado e para a viabilização de acesso a determinados recursos financeiros, além de disponibilizarem treinamentos e assistência técnica (SCHULTZ, 2011). Superar a carência dessas relações contribuiria para a valorização da atividade profissional dos assentados, o que estimularia a sua participação, caso se sentissem parte de um grupo que possui uma consciência relacionada às questões ambientais e que produz de forma ambientalmente correta, o que ocorre com mais nitidez entre os associados da ADESSU.

Para isso, a organização do grupo deve ser trabalhada como um instrumento da ação coletiva a ser determinado em relação a um conjunto de ações ou funções, mas restaria distinguir, segundo Crozier e Friedberg (1977), os principais motores dessa ação coletiva. Para atender a situações de interdependência entre atores heterogêneos, a ação coletiva é implementada por meio de "instituições", definidas como um conjunto de regras e normas que são efetivamente aplicadas por um grupo de indivíduos para organizar atividades. As normas correspondem a valores internos do grupo, e as regras são representações compartilhadas com o exterior, e eventualmente sujeitas a sanções (OSTROM, 1998). Acolhendo esses apontamentos do autor, a ação coletiva depende da capacidade de elaboração e adaptação de regras comuns; a institucionalização dessas regras no grupo pode ser um incentivo à cooperação e ao compartilhamento, duas estruturas a serem fortalecidas no assentamento.

\section{CONSIDERAÇÕES FINAIS}

A pesquisa revelou que, no caso da ADESSU, as instituições e organizações envolvidas atuaram de forma efetiva no processo formativo do grupo, participando no planejamento das ações, articulando o vínculo dos associados com outros atores locais, financiando projetos, socializando o conhecimento agroecológico e apoiando as práticas agrícolas iniciais. No assentamento Chico Mendes III, a participação das instituições e organizações presentes visava elaborar projetos, oferecer serviços de ATER, introduzir novas metodologias de trabalho, promover a organização social dos agricultores e realizar intercâmbios e capacitações junto aos assentados.

Essa abordagem comparativa permitiu observar a participação dos atores na construção de fatores qualitativos que compõem a sustentabilidade das estratégias e experiências de desenvolvimento rural orientadas pela Agroecologia. A análise dos dois casos mostra que Santa Cruz da Baixa Verde possui uma dinâmica de desenvolvimento rural apoiada em múltiplos fatores: presença de organizações governamentais e não governamentais; redes sociais estruturadas e de variada natureza; agentes financeiros; e atuação simultânea de agricultores familiares locais, associações e sindicatos por uma causa comum. Enquanto isso, São Lourenço da Mata é um bom exemplo de uma experiência desencadeada por um fator quase unilateral: a intervenção de uma instituição de ensino por meio de projetos de pesquisa e extensão universitária, com foco na transição agroecológica.

Redes sociais estruturadas, envolvendo outros atores, e a capacidade da ADESSU de atuar como coordenadora dos ativos locais preexistentes influenciaram positivamente o processo de transição agroecológica de Santa Cruz da Baixa Verde. Isso ocorreu porque tanto as redes sociais como a atuação coordenadora da ADESSU foram decisivas na construção de condições qualitativamente melhores do que aquelas identificadas no assentamento Chico Mendes III, como contínua formação agroecológica para seus associados, base de conhecimento agroecológico nas instituições integradas à ADESSU, acesso a políticas públicas voltadas ao meio rural e menor dependência de agentes externos. 
Apesar das taxas de crescimento econômico e da diversificação produtiva alcançadas no assentamento por conta da transição agroecológica, no Chico Medes III se evidenciam problemas nas interações entre atores, que podem limitar as condições para a sustentabilidade do desenvolvimento rural, na medida em que não têm influência positiva na configuração qualitativa dessa dinâmica. O próprio processo de transição agroecológica mediante projetos universitários talvez tenha limitado desde o início o fortalecimento de uma rede social mais local e incentivado a atração de atores externos. Isso se torna ainda mais problemático quando se leva em consideração a dependência dos assentados em relação aos incentivos fornecidos pela UFRPE. Os agricultores do Chico Mendes III, por vezes, não conseguem responder às demandas que acompanham a transição agroecológica em curso. Uma estratégia de desenvolvimento rural baseada em incentivos de atores externos como modo de impulso não é ruim em si mesma, mas, para ser sustentável no tempo, acredita-se que outros atributos qualitativos devam ser criados ao longo da experiência. A falta de mercados consolidados para escoar a produção, a ausência dos serviços de ATER e a própria falta de organização associativa entre os agricultores são fatores que compõem uma frágil estrutura de desenvolvimento rural de longo prazo.

Não se trata de concluir que a ADESSU é um caso de sucesso e o Chico Mendes III tem suas limitações, ou de sugerir uma replicação do caso da associação. Não se trata, tampouco, de assumir a posição de que cada caso é um caso e que ambos devem ser observados apenas em suas especificidades. O curso do processo de transição agroecológica altera-se no tempo, por isso mesmo não é possível se basear em modelos pré-estabelecidos. Por mais que tenha surgido de bases relativamente frágeis no que tange à sua sustentabilidade, a estratégia de desenvolvimento rural do município de São Lourenço da Mata sofreu mudanças significativas ao longo do tempo: hoje há maior participação dos assentados na transição agroecológica, que tentam agir de forma coletiva, demandando mudanças na forma de se produzir, buscando maior resposta dos entes públicos para as demandas de infraestrutura no assentamento, além da criação de feiras agroecológicas, com o objetivo claro de estimular um ambiente mais voltado para o conhecimento agroecológico e a agricultura sustentável.

O fato é que, tanto quanto a escolha de estratégias adequadas para o desenvolvimento rural sustentável, a capacidade de readaptá-las em face das mudanças de cenário e de aprender com as experiências alheias são determinantes, no longo prazo, para o sucesso desse tipo de iniciativa. Entendendo que a transição agroecológica está permanentemente sujeita a reorientações, espera-se ter demonstrado de que maneira atores e redes sociais podem influenciar o desenvolvimento rural; que é possível identificar fatores que qualitativamente produzem diferenças entre casos concretos; e que tais fatores podem levar a dinâmicas mais ou menos sustentáveis no tempo.

\section{REFERÊNCIAS}

ABRAMOVAY, R. O futuro das regiões rurais. 2. ed. Porto Alegre: Editora da UFRGS, 2009.

ALTIERI, M. Agroecologia: bases científicas para uma agricultura sustentável. 3. ed. rev. ampl. São Paulo: Expressão popular; Rio de Janeiro: AS-PTA, 2012.

CAPORAL, F. R.; COSTABEBER, J. A. Agroecologia: alguns conceitos e princípios. Brasília: MDA/SAF/DATERIICA, 2007. 
CASTELLS, M. O poder da identidade. 6. ed. São Paulo: Paz e Terra, 2008.

CASTILLA, E. J.; HWANG, H.; GRANOVETTER, E.; GRANOVETTER, M. Social networks in Silicon Valley. In: MOON LEE, C.; MILLER, W. F.; HANCOCK, M. G.; ROWEN. H. S. (Ed.). The Silicon Valley edge: a habitat for innovation and entrepeneurship. San Francisco: Stanford University, 2000.

CASTORIADIS, C. A instituição imaginária da sociedade. Rio de Janeiro: Paz e Terra, 1982.

COSTABEBER, J. A.; GARRIDO, F.; MOYANO, E. Ação coletiva e transição agroecológica: uma análise de experiências associativas em agricultura ecológica. In: WORLD CONGRESS OF RURAL SOCIOLOGY, 10., 30 jul./5 ago. 2000, Rio de Janeiro. Anais [...]. Rio de Janeiro: IRSA, 2000. p. 1-13.

CROZIER, M.; FRIEDBERG, E. L'acteur et le système. Paris: Le Seiul, 1977.

GEILFUS, F. 80 herramientas para el desarrollo participativo: diagnóstico, planificación monitoreo y evaluación. San José: IICA, 2009.

GOMES, J. C. C.; BORBA, M. F. S. Limites e possibilidades da Agroecologia como base para sociedades sustentáveis. Ciência \& Ambiente, Santa Maria, v. 29, p. 5-14, jul./dez. 2004.

GRANOVETTER, M.; SWEDBERG, R. The Sociology of Economic Life. 3. ed. Boulder, CO: Westview Press, 2011.

OSTROM, E. A behavioral approach to the rational-choice theory of collective action. American Pollitical Science Review, v. 92, n. 1, mar. 1998.

SCHMITT, C. J. Redes, atores e desenvolvimento rural: perspectivas na construção de uma abordagem relacional. Sociologias, Porto Alegre, ano 13, n. 27, maio/ago. 2011, p. 82-112.

RADOMSKY G, F. W. Reciprocidade, redes sociais e desenvolvimento rural. In: SCHNEIDER S. (Org.). A diversidade da agricultura familiar. Porto Alegre: Editora da UFRGS, 2006.

SABOURIN, E. Práticas sociais, políticas públicas e valores humanos. In: SCHNEIDER S. (Org.) A diversidade da agricultura familiar. Porto Alegre: Editora da UFRGS, 2006.

SCHULTZ, G. Relações com o mercado e (re) construção das identidades socioprofissionais na agricultura orgânica. In: SCHNEIDER, S.; GAZOLLA, M. (Org.). Os atores do desenvolvimento rural: perspectivas teóricas e práticas sociais. Porto Alegre: Editora da UFRGS, 2011.

\section{Sobre o autor:}

Filipe Augusto Xavier Lima: Professor Adjunto na área de Extensão e Desenvolvimento Rural, vinculado ao Departamento de Economia Agrícola (DEA) do Centro de Ciências Agrárias (CCA) da Universidade Federal do Ceará (UFC). E-mail: filipeaxlima@hotmail.com 
